These studies prompted us to review the thyroid scans of euthyroid and hyperthyroid patients referred to our institute for thyroid diagnosis since 1966. Scans are made routinely of nearly all patients except some young children. Two categories of patients were excluded: those who previously had undergone thyroid surgery, and those with hyperfunctioning nodules as the only visible thyroid tissue on the scan. The remaining 452 scans, 318 in euthyroid and 134 in hyperthyroid patients, were further divided into four subgroups: (a) normal (no nodules, estimated thyroid weight $30 \mathrm{~g}$. or less); (b) diffusely enlarged; (c) solitary nodule ; and $(d)$ multinodular. Normal thyroids were more common in euthyroid than in hyperthyroid patients: 117 out of $318(37 \%)$ and 16 out of 134 (12\%), respectively. Diffusely enlarged thyroids and those with multiple nodules were found more frequently in hyperthyroid patients.

TABLE I.-Thyroid Asymmetry in Euthyroid Patients

\begin{tabular}{|c|c|c|c|c|}
\hline & $\mathbf{R}>\mathbf{L}$ & $R=L$ & $R<L$ & To \\
\hline \multirow{3}{*}{$\begin{array}{l}\text { Normal } \\
\text { Diffusely } \\
\text { enlarged } \\
\text { Solitary } \\
\text { nodule } \\
\text { Multinodular }\end{array}$} & & 44 & $17\left(15^{\circ}\right.$ & 11 \\
\hline & $34(60 \%$ & $12(21 \%)$ & $11(19 \%)$ & \\
\hline & $\begin{array}{l}47(52 \%) \\
22(44 \%)\end{array}$ & $\begin{array}{l}19(21 \%) \\
11(21 \%)\end{array}$ & & \\
\hline
\end{tabular}

R, Right lobe; L, left lobe; \%, per cent of total in suboroup.

TABLE II.-Thyroid Asymmetry in Hyperthyroid Patients

\begin{tabular}{l|ccc|c}
\hline Subgroup & $\mathbf{R}>\mathbf{L}$ & $\mathbf{R}=\mathbf{L}$ & $\mathbf{R}<\mathrm{L}$ & Total \\
\hline \begin{tabular}{l|rrr} 
Normal \\
Diffusely
\end{tabular} & $6(38 \%)$ & $6(38 \%)$ & $4(25 \%)$ & 16 \\
$\begin{array}{l}\text { enlarged } \\
\text { Solitary }\end{array}$ & $19(56 \%)$ & $6(18 \%)$ & $9(27 \%)$ & 34 \\
$\begin{array}{l}\text { nodule } \\
\text { Multinodular }\end{array}$ & $23(48 \%)$ & $11(23 \%)$ & $14(29 \%)$ & 48 \\
& $17(47 \%)$ & $4(11 \%)$ & $15(42 \%)$ & 36
\end{tabular}

R, Right lobe; L, left lobe; \%, per cent of to:a! number in subgroup.

The analysis of thyroid asymmetry is shown in Tables I and II. Cases in which both lobes were of approximately equal size occurred more frequently in the normal thyroid subgroups (38\%) than in other subgroups (11-23\%). In all subgroups except those with multiple nodules, cases in which the right lobe was larger than the left lobe were more common than those in which the reverse was true. This difference appeared to be more pronounced in euthyroid cases (137 v. 53) than in hyperthyroid patients (48 v. 27). Also, solitary nodules were found more frequently in the right lobe than in the left lobe, both in euthyroid and hyperthyroid patients (Table III).

\section{TABLB III.-Position of Solitary Thyroid Nodules}

\begin{tabular}{l|l|} 
Clinical Diagnosis & Right Lobe Isthmus Left Lobe \\
\cline { 1 - 2 } & .
\end{tabular}
Euthyroid .. $39(43 \%) 31(34 \%) 21(23 \%)$ \begin{tabular}{l|lll} 
Hyperthyroid .. & $20(48 \%)$ & $13(31 \%)$ & $9(22 \%)$
\end{tabular} $\%$, Per cent of patients with the same clinical diag

In conclusion, the finding of a high frequency of thyroid asymmetry in normal thyroid glands, with larger right lobes predominating, ${ }^{12}$ was confirmed and extended to pathological glands of euthyroid and hyperthyroid patients. In multinodular glands, however, larger left lobes were about as numerous as larger right lobes. The predominant occurrence of solitary thyroid nodules in the right $\operatorname{lobe}^{3-6}$ was also confirmed. The richer vascularization of the right lobe has been proposed as an explanation. ${ }^{3}-$ We are, etc.,

JAN D. WIENER.

Department of Medicine and Peter Roos. \section{Clinical Radiochemical Institute Academich Ziekenhuis der Vrije Universiteit,
Amsterdam, Holland.}

\section{REFBRENCBS}

1 Thomson, J. A., Lancet, 1966, 2, 308.

Orr, F. R., and' Ingham, G. K., Lancet, 1967, 2 , 262.

Artagaveytía, D., Degrossi, O., Gorta, H. H and
Pecorini, V., Rev. clin. esp., 1965, 98, 266. Conte, N., and Ziliotto, D., Acta isotop., 1964,

4, 197. M. P., Minerva med., 1965, 56, 1814.

Ziliotto, D., Conte, N. , and Scandellari, C., Folia

endocr.s $1966,19,76$.

$1967,78,1097$

\title{
Chemotherapy of Tuberculosis
}

SIR,-Dr. V. C. Barry, whose work I quoted in the article on "Experimental Chemotherapy of Tuberculosis" (13 July, p. 75), has drawn attention to three errors concerning the phenazines, for which I apologize :

(1) The phenazines were not derived from lichens ; they were wholly synthetic.

(2) The correct reference to the description of the rimino compounds is the report by Dr. Barry and his colleagues in Nature (Lond.), 1957, 179, 1013.

(3) Fig. 4 represents anilinoaposafranine. The riminophenazines have an alkyl or cyclo-alkyl group substituted for the $\mathrm{H}$ in the imino (=NH) group. Chlorophenyl groups are attached at the $R$ positions in the compound $B 663$.

-I am, etc.,

St. George's Hospital,
London S.W.1.

JOHN BATten.

\section{Propranolol in Hypertension}

SIR,-I was interested to read the divergent views expressed by Drs. G. S. Humphreys and D. G. Delvin (8 June, p. 601) of the ineffectiveness of propranolol in hypertensive Jamaicans.

I should like to comment on their observations as a result of $\mathrm{my}$ experience with propranolol in white hypertensives. I have found that there are two important factors which deserve emphasis, namely, the duration of therapy and the dosage required to lower the blood pressure satisfactorily. Our own work (see Table) ${ }^{2}$ shows that a significant response was obtained when using a maximum dose of $400 \mathrm{mg}$. daily, the effective dose being frequently in excess of that used by Drs. Humphreys and Delvin. Since that time further experience has convinced me that higher dosage may be necessary in order to achieve a therapeutic response in patients who have previously been difficult to manage. Prichard's ${ }^{2}$ work lends additional support to the fact that higher dosage than $360 \mathrm{mg}$. daily is necessary to achieve a satisfactory control. Furthermore, duration of therapy has also been shown to be important. It would be interesting to know whether any difference was found between that group who had propranolol continuously for four months and those who had a continuous treatment of two months.

I suggest that a re-analysis of clinical terms should be considered. The current therapy for the treatment of hypertension for the most part involves the sympathetic neurone blocking agents, and while these drugs are capable of lowering blood pressure in the upright position they are not so effective when the person is supine. The same, of course, applies to the control of arterial pressure on exercise. This is a significant point in consideration of any antihypertensive agent. There are several reports suggesting that postural and exercise hypotension hardly ever occur when hypertensive patients are treated with propranolol. Our own work amply confirms these findings.

Prichard ${ }^{3}$ has postulated that the mode of action of propranolol in hypertension is due to adaptation of baroreceptors, while Frohlich considers that it is due to heart rate dependent fall in cardiac output. Drs.

Mean Blood Pressures

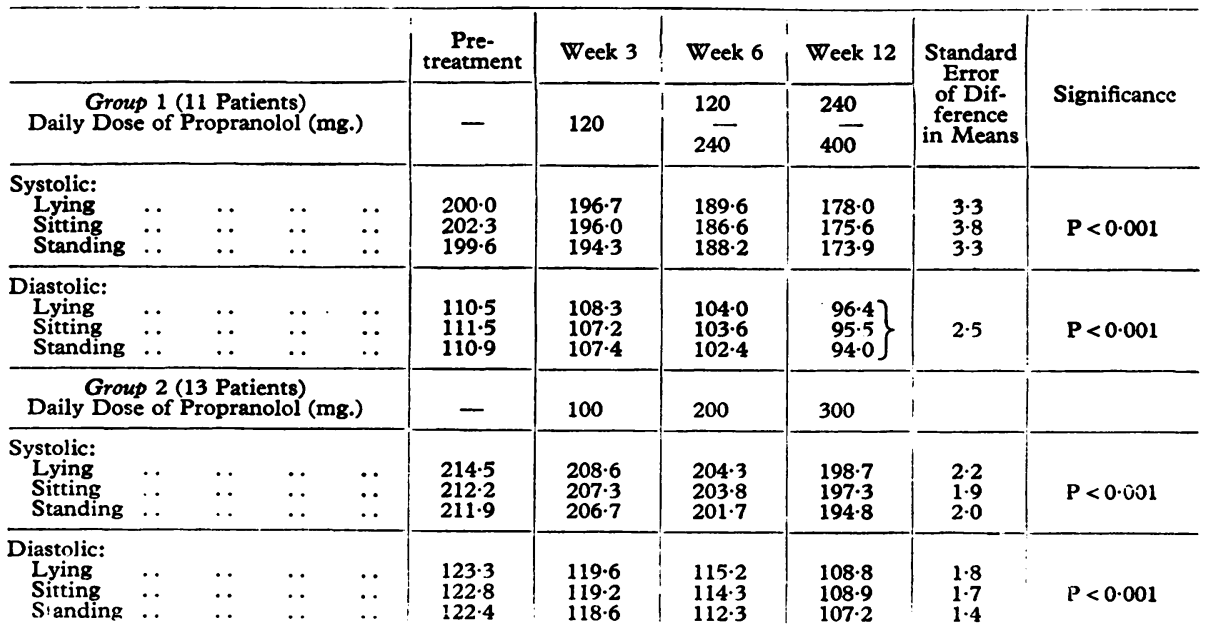


Humphreys and Delvin postulated a central action, yet when they emphasize the ineffectiveness of the drug it is certainly worth noting that eight of these patients, that is to say, nearly half of them, had a fall in supine diastolic pressure, in spite of the fact that they say that Jamaicans occupy an intermediate position on the scale and that they do not suffer from stress-induced hypertension which is frequently seen in Europeans. Therefore any "tranquillizing effect" of the drug would not be expected to show any beneficial results. There is therefore a certain degree of discrepancy in the fact that they consider the antihypertensive effect of the drug to be due to some form of tranquillizing action, yet stress-induced hypertension is not seen in Jamaicans.-I am, etc.,

\section{S. N. TEWARI.}

Royal Albert Edward Infirmary, Wigan (Lancs.).

\section{REFERENCES}

1 Tewari, S. N., and Grant, R. H. E., Postgrad. Med. F., (in press)

Prichard, B. N. C., Proc. Roy. Soc. Med., 1968 Vol. 61 , No. 5.

- Prichard, B. N. C., and Gillam, P. M. S., Am. F. Cardiol., 1966, 18, 387.

- Frohlich, E. D., Tarazi, R. C., Dustan, H. P., and Page, I. H., Circulation, 1968, 37, 417.

\section{Antibiotic Cover in Dentistry}

SIR,-Mr. R. A. Peebles (22 June, p. 762) comments on the inference that "the onset of the disease was related to the performance of dental treatment" in our first patient with hypertrophic obstructive cardiomyopathy who developed infective endocarditis. Clinically there was no doubt that the symptoms of malaise with profuse night sweats became apparent after the dental manipulation. We therefore assumed that our patient may have developed a bacteraemia at the time of the dental treatment and that this led to endocarditis. We must point out that unfortunately we have no more details of our patient's dental treatment; we also do not know what tie state of his teeth and gums was at the time.

Mr. Peebles is quite right to point out that fillings, in the absence of periodontal disease, are not usually a cause of bacteraemia, although a few cases have been reported in the literature ${ }^{2}$ We agree that fillings alone are not normally dangerous. It would be a counsel of perfection but unnecessary and impracticable to cover all dental fillings, however minor, in susceptible subjects. None the less, failing to do so may rarely be followed by endocarditis. Positive blood cultures have also been reported after mere brushing of the teeth $^{3}$ and post-prandially, ${ }^{4}$ so complete protection would involve wholesale dental clearance. We therefore advise antibiotic cover only for extractions, scalings, and extensive fillings or when there is periodontal disease.

We probably should have been more explicit in our paper and accept Mr. Peebles's implied criticism. Nevertheless in the regrettable absence of more details about the type of dental therapy we cannot say whether or not it was relevant to the subsequent illness. The point of mentioning it at all was really to help drive home the message of our paper that heart muscle disease unlike valve disease or septal defect is not generally recognized to be at risk from infective endocarditis and therefore in need of prophylactic antibiotics when appropriate.-We are, etc.,

\section{R. J. VeChT.}

C. M. OARLeY.

Department of Medicine, Royal Postgraduate Medical School,
London $W .12$.

\section{RBFERENCES}

Wagner, R. P., and Kruger, G. O., $41 s t$ Gen. meeting, Int. Assoc. Dent. Res., March 1963 ,

135, Chicago. Cardiol., 196i, 7, 793. Cobe, H. M., Oral' Surg. Oral Med. Oral Path.,

Murray, M., and Moosnick, F., f. Lab. and Clin. Med., 1940-41, 26, 801 .

\section{Hypothyroidism and ${ }^{131}$ I Therapy}

SIR,-There has been considerable criticism of the treatment of thyrotoxicosis by radioiodine (18 May, p. 427, and $27 \mathrm{July}$, p. 250) because of the development of myxoedema tending to occur over the years after the radioiodine has been administered. Some of this myxoedema must doubtless be considered inevitable owing to a gradual failure of the gland starting before the administration of radioiodine even though it has been preceded by the development of thyrotoxicosis.

In carrying out thyroid tests $I$ have been struck by the fact that sometimes the function is partly physiological and partly pathological as indicated by the possibility of suppressing part of the function of the gland by the administration of triiodothyronine $\left(T_{3}\right)$ before the test is carried out. The chief component of the radiation from ${ }^{121} \mathrm{I}$ is betaradiation, and, judging from the fact that the use of external radiation is less efficient, it would appear that the effect of radioiodine in destroying the function of the gland is mostly by virtue of the beta component. The implication of this is that the effect of all the radiation will be very local and will not extend much, if at all, beyond the cells that have taken up the radioiodine. Assuming, therefore, that it is desirable to destroy pathological tissue and to leave physiological tissue intact it would seem reasonable to give the treatment dose of radioiodine after a course of $T_{3}$ so as to suppress any physiological thyroid tissue which is present. This procedure, for cases in which it is considered safe to use $T_{3}$ in the presence of thyrotoxicosis, would seem to offer the possibility of limiting hypothyroidism to those cases in which it may be unavoidable. Moreover, smaller repeated doses to treat the pathological cells should be a rational method of treatment.-I am, etc.,

\section{Radiotherapy Department, \\ The Churchill Hospital
Headington, Oxford.}

Frank Ellis.

\section{E.E.G. Signs of Death}

SIR,-Your leading article (11 May, p. 318) and letters (1 June, p. 557; 22 June, p. 762 and 20 July, p. 185) prompt us to write of our experience of the E.E.G. in drug-induced coma. Since January 1968, among 48 poisoned patients studied electroencephalo- graphically, 12 were deeply unconscious and unresponsive to any stimuli. Five of these 12 had flat electroencephalographic tracings for up to 11 hours. One patient died, and the remainder have made a complete clinical recovery.

As an example, one 63-year-old female who had taken a large dose of sodium barbitone was admitted deeply unconscious and unresponsive to all stimuli. Her E.E.G. showed complete electrical silence. Eight hours after her admission her E.E.G. for the first time showed slight activity but continued almost flat (Fig. 1). There was still no clinical response to stimuli. The E.E.G. activity gradually increased to generalized slow waves, as shown in Fig. 2. The E.E.G. one month later was within normal limits.

$F=C_{2} C_{2}$

$C z-P=$

$F Z-F_{4}$

$F \geq-F 3$

$c z-c 4$

C. -.53

$P_{Z}=P_{4}$

$\begin{array}{ll}P_{z}-P_{3} & \int^{100 \mu \mathrm{V}} \\ T C=0.3 \text { seC. }\end{array}$

FIG. 1.-Eight hours after admission the E.E.G. continues almost flat.

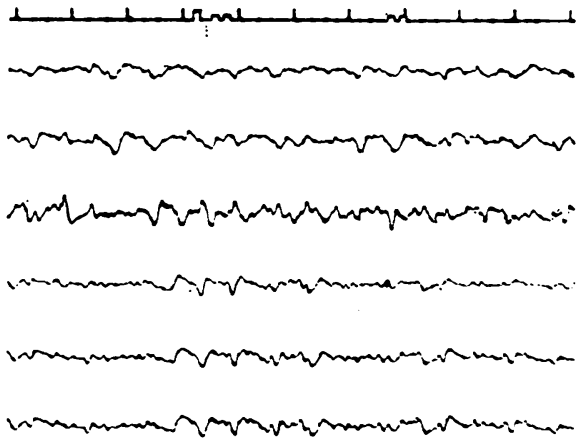

FIG. 2.-Twenty-six hours after admission the E.E.G. shows generalized slow activity.

It is important to bear in mind that flat E.E.G. records are not uncommon in patients who have ingested large quantities of drugs which depress the central nervous system, and that complete recovery can occur. It is also worthy of note that patients who at first have complete electrical silence may not show any clinical response to stimuli for as long as 15 hours, yet the E.E.G. may show progressive increase in electrical activity. Such a record can be of value prognostically.-We are, etc.,

IJAZ HAIDER.

IAN OSWALD.

HenRy Matthew.

Regional Poisoning Treatment Centre, The Royal Infirmary, Edinburgh. 